\title{
Emotional Impact of Patient Safety Incidents on Family Physicians and Their Office Staff
}

\author{
Maeve O'Beirne, MD, PhD, CCFP, Pam Sterling, BSc, Luz Palacios-Derflingher, PhD, \\ Stacey Hohman, BScH, and Karen Zwicker, BScH
}

Objective: The objective of this study was to investigate the emotional responses and coping strategies that family physicians and their office staff reported in response to a patient safety incident.

Method: Two questions contained in a patient safety incident report developed for a study of patient safety in family practice were analyzed. The questions asked reporters to indicate their emotional response to a patient safety incident and how they coped with it. A total of 264 confidential patient safety incident reports collected from September 2007 to August 2010 were analyzed.

Results: An emotional response was reported on $82.4 \%$ of reports. Of those reports on which an emotional response was reported, a coping strategy was reported on $62.8 \%$. The top 4 reported emotional responses were frustration (48.3\%), embarrassment (31.5\%), anger (12.6\%), and guilt (10.1\%). Physicians reported an emotional response more often than clinic staff. An emotional response was reported more often when there was a possibility of harm. Coping strategies were reported as follows: $52 \%$ talked to someone about the incident, $37.2 \%$ did nothing in response to the incident, $17.9 \%$ told the patient about the incident, and 3.6\% did something else. Female physicians reported using coping strategies less often than male physicians. A coping strategy was reported more often when there was a possibility of harm.

Conclusions: All members of the health care team report experiencing emotions related to patient safety incidents in their practice. Incidents with minor or no harm still invoked emotional responses from the providers. It is important to understand the impact that patient safety incidents have on the medical clinic as a whole. (J Am Board Fam Med 2012;25:177-183.)

Keywords: Coping Skills, Family Medicine Research, Medical Errors, Patient Safety

A patient safety incident is an event or process that could have resulted or did result in unnecessary harm to a patient. ${ }^{1}$ Patient safety incidents affect both the patient and caregivers. ${ }^{2-4}$ Much work has been done studying the effect of incidents on patients, ${ }^{5,6}$ but examining the effect on caregivers, also referred to as "the second victim," ${ }^{2-4}$ is in its infancy. Previous studies have focused on the acute care system and medical residents ${ }^{7-16}$ or a compi-

This article was externally peer reviewed.

Submitted 5 May 2011; revised 23 September 2011; accepted 12 October 2011.

From the Department of Family Medicine (MO, LPD, $\mathrm{SH}, \mathrm{KZ}$ ) and Community Health Sciences (MO), University of Calgary, Canada.

Funding: This project is funded by Canadian Health Services Research Foundation, Canadian Patient Safety Institute and Alberta Heritage Foundation for Medical Research. Conflict of interest: none declared.

Corresponding author: Maeve O'Beirne, W21C Research Centre, G-01 TRW Building, 3280 Hospital Drive NW, Calgary AB, Canada, T2N 4Z6 (E-mail: obeirne@ucalgary.ca). lation of acute and primary care. ${ }^{17-20}$ Only 2 studies have explored the emotional impact of incidents on primary care providers alone. ${ }^{21,22}$ The first explored the emotional impact of the most memorable mistake on the family physician and his or her response to a hypothetical scenario. ${ }^{21}$ The second used focus groups of family physicians and residents to develop a reference statement for the appropriate management of mistakes in the training environment. $^{22}$

Other research, primarily in acute care, found that health professionals have varied emotional responses to incidents. The most common emotions include guilt, ${ }^{13,15,16,20,22}$ anxiety, ${ }^{13,15,19,20}$ anger, ${ }^{14,15,22}$ shame, ${ }^{16,21}$ and embarrassment. ${ }^{13,15}$ Because health professionals believe that they should not make mistakes, ${ }^{16,20}$ these emotions can imprint permanent or long-lasting consequences, ${ }^{14-16}$ including loss of self confidence, ${ }^{14-16,19,21}$ sleeplessness, ${ }^{14,15,19,20}$ selfblame, ${ }^{16,21}$ reduced job satisfaction, ${ }^{14,19}$ anxiety about 
a harmed reputation, ${ }^{15,16,19,20}$ and fear of a lawsuit or disciplinary action. ${ }^{13-15,20}$ Being involved in an incident can be related to future suboptimal patient care ${ }^{23}$ and consequential errors. ${ }^{19,23}$

As well as understanding the emotional impact of an incident on providers, it is also important to understand how providers cope with their emotions. Physicians often do not discuss their mistakes with anyone because of fears of humiliation, litigation, punishment, or admitting imperfection. ${ }^{15,18,21}$ When they do seek solace it is most likely to be with a significant other ${ }^{14,15,18,20,21}$ or a trusted colleague. ${ }^{13,15,18,20}$ Most often, though, there is a failure to receive support from colleagues, ${ }^{15,21,24}$ and this causes an inability to move forward ${ }^{14}$ and promotes limited self- and organizational learning. ${ }^{24}$ The most difficult challenge providers face is forgiving themselves. ${ }^{20}$ These maladaptive coping strategies put them at considerably increased risk for burn-out and depression. ${ }^{23}$ Physicians may require professional help ${ }^{17}$ to accept their fallibility. Because of the shortage of family physicians, ${ }^{25}$ it is important to look at the emotional impact of incidents on family medicine providers.

$\mathrm{Wu}^{3}$ and Penson et $\mathrm{a}^{16}$ noted that all members of the health care team are susceptible to incidents and are vulnerable to their outcomes. When Wolf et $\mathrm{al}^{13}$ examined the responses to and concerns about medication errors in acute care, they collected information from multiple providers, including nurses, physicians, and pharmacists. The emotional impact and consequences of an incident on different provider types is not well known. ${ }^{24}$ Many family physicians work in teams, and it is important to understand how patient safety incidents affect all members of the team.

Little is known about the relationship between incident severity and level of distress among caregivers. ${ }^{24}$ Waterman et $\mathrm{al}^{19}$ have found that physician distress after incidents is not limited to the occurrence of serious incidents. In family medicine the majority of reported incidents are either close calls (no known harm) or incidents of minor harm to the patient. ${ }^{26-29}$ Thus, when examining the emotional impact of incidents it is important to include all incidents, not just ones resulting in serious patient harm.

This article examines the immediate emotional responses of family physicians and their office staff to patient safety incidents in community settings. It also documents coping strategies used by these providers and the relationship between emotional response and severity of the incident.

\section{Methods}

The Medical Safety in Community Practice (MSCP) program, operating within the Alberta Health Services' Calgary zone, created a safety learning system. ${ }^{30}$ The incident reporting form associated with this system had 2 questions that asked reporters to indicate their emotional response to the incident (question 3, "What emotional impact did this incident have on you?") and how they coped with it (question 4, "What did you do with your emotions?"). ${ }^{30}$ The available responses to emotional response were anger, blame, embarrassment, frustration, guilt, none, relief, sadness, self doubt, shame, and other. The available responses to how the incident was coped with were nothing, talked about it, told the patient, and other. Development of the form is described elsewhere. ${ }^{30}$ There was no direct follow-up with providers or staff concerning their responses.

All members (physicians, nurses, office staff, and office managers) of 19 participating family medicine practices used a 1-page form to report confidentially incidents they deemed to be patient safety incidents. Forms were submitted either online or by fax. Data were collected from September 2007 to August 2010.

\section{Analysis}

Reports were divided into discrete groups by provider type: physicians and clinic staff (includes nurse, office staff, and office managers). Frequencies, $\chi^{2}$ tests (Fisher exact test when needed), tests of proportions, and multilevel Rasch models were determined using SPSS version 16 (SPSS Inc, Chicago, IL) and R (available at http://www.r-project. org/). ${ }^{31}$ A significance level of 0.05 and $95 \%$ confidence intervals were used.

The 2 variables "emotional response" and "coping strategy" from questions 3 and 4, respectively, were analyzed. Multivariate logistic regression analysis was performed to assess the relationship of the set of multiple types of emotional response as a reply with sex and physician/clinic staff, taking into account that several reports may pertain to the same person. The multivariate set of responses consisted of the 4 emotional impacts, with the 
highest observed frequency and reporter identification included as random terms. Because the response variables were each dichotomous (yes/no), a multilevel Rasch model was implemented. ${ }^{32}$ For the remaining analyses, to cope with the many types of emotional responses and multiple combinations of these, replies were grouped in 2 levels: emotional response/no emotional response.

Reports that indicated an emotional response were cross tabulated with provider type, severity of harm, and duration of harm. Similarly, the variable coping strategy was cross tabulated with provider, severity, and duration of harm.

\section{Results}

Of the 264 incident reports, 26 reports were incomplete (8 did not indicate an emotional response, 14 did not indicate a coping strategy, 1 was missing both, and sex of the reporter could not be determined on 3 reports) and were excluded, leaving 238 reports.

There were 53 unique reporters: 26 (49\%) were physicians and $27(51 \%)$ were clinic staff (nurses $[\mathrm{n}=11,21 \%]$, office staff $[\mathrm{n}=14,26 \%]$, and managers $[\mathrm{n}=2,4 \%])$. Of the 238 incident reports, 138 (58\%) were submitted by physicians and $100(42 \%)$ were submitted by clinic staff (nurses $[\mathrm{n}=35,15 \%]$, office staff $[\mathrm{n}=58,24 \%]$, and managers $[\mathrm{n}=7,3 \%])$.

Types of incidents reported included documentation $(\mathrm{n}=107,41.4 \%)$; medication $(\mathrm{n}=77$,

Table 1. Severity and Duration of Harm

\begin{tabular}{lrr}
\hline & $\mathrm{N}$ & $\%$ \\
\hline Severity of harm & & \\
None & 133 & 55.9 \\
Mild & 58 & 24.4 \\
Moderate & 21 & 8.8 \\
Severe & 3 & 1.3 \\
Not sure & 16 & 6.7 \\
Missing & 7 & 2.9 \\
Total & 238 & 100.0 \\
Duration of harm & & \\
None & 154 & 64.7 \\
Temporary & 52 & 21.8 \\
Permanent & 1 & 0.4 \\
Not sure & 29 & 12.2 \\
Missing & 2 & 0.8 \\
Total & 238 & $99.9^{*}$ \\
\hline
\end{tabular}

*Does not add up to 100 because of rounding.
Figure 1. Number of emotional responses selected per reported patient safety incident.

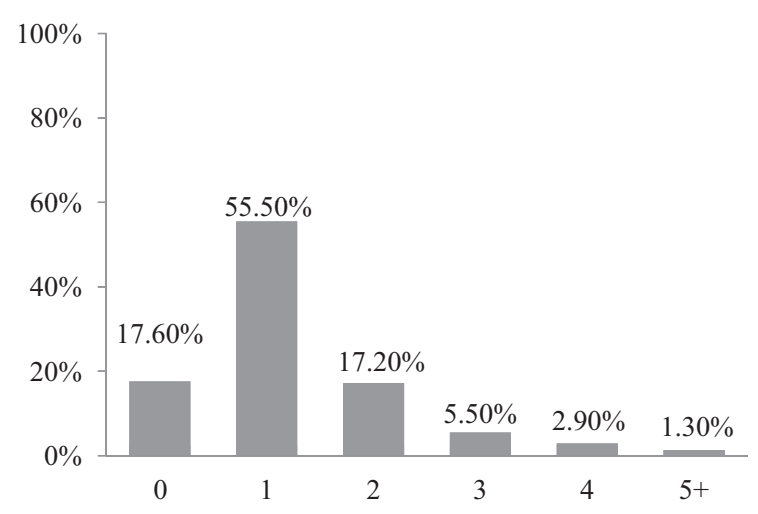

29.7\%); clinical ( $\mathrm{n}=48,18.7 \%$ ); and clinical process $(n=45,17.5 \%)$. For further details see O'Beirne et al. ${ }^{33}$ Table 1 indicates the severity and duration of patient harm.

\section{Reported Emotional Responses}

The MSCP reporting form listed 9 commonly reported emotional responses plus an open-ended "other" option and a "none" option. Reporters were allowed to select more than one response. On the 238 reports, 342 responses were reported. Figure 1 displays the number of emotional responses indicated by each reporter.

The top 5 reported emotional responses were frustration $(48.3 \%)$, embarrassment $(31.5 \%)$, anger (12.6\%), guilt $(10.1 \%)$ and blame $(5.5 \%)$. Not having an emotional response was indicated on $17.6 \%$ of reports (Figure 2).

\section{Relationship Between Types of Emotional Response and} Sex, Individual Provider Type, and Clinic Staff Grouped Of the 238 reports, 189 (79.4\%) were submitted by women, including physicians, nurses and office staff. There were no male clinic staff in the program. Of the 26 physicians who submitted reports, $69.2 \%$ were women and $30.8 \%$ were men. The 4 emotional responses with highest frequency were frustration, embarrassment, anger, and guilt (see Figure 2). Sex was related to the top 4 emotional responses (estimate of $\beta$ is $0.7862 ; P=.03$ ). The probability of a man reporting any one of frustration, embarrassment, anger, or guilt was greater than that of a woman reporting any one of these emotions. Because both sexes are present only in the physician group, a subanalysis of this 
Figure 2. Reported Emotional Responses.

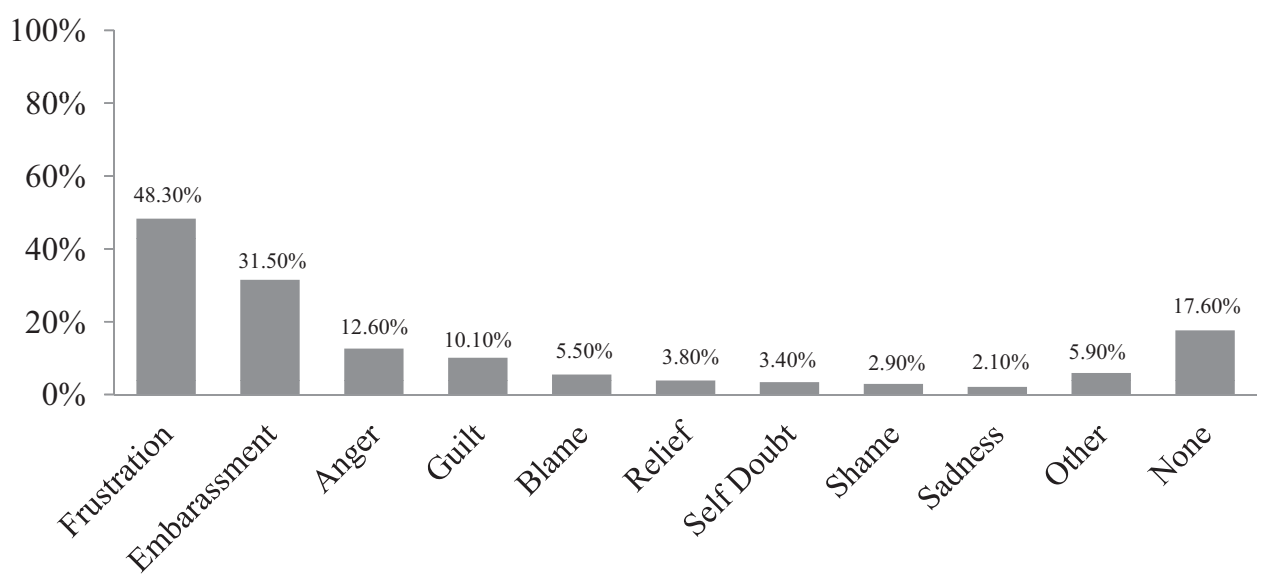

group was performed to assess the relationship of the emotional responses with reporter sex. Within physician groups there was no significant sex effect.

Having an Emotional Response Versus Provider, Severity, and Duration of Patient Impact

Responses were grouped into 2 categories: those who responded with an emotional response and those who responded "none." Overall, 82.4\% (n = 196) of reports had an emotional response. Table 2 illustrates the relationship between having an emotional response versus provider type.

Severity of the incident (none, mild, moderate, severe, fatal, not sure) was not associated with emotional response $(P=.068)$, but duration of harm (none, temporary, permanent, not sure) was associated with emotional response $(P=.007$, Fisher exact test). Further analysis examined "no duration" versus "some duration" (temporary or permanent). An emotional response was reported more often when there was a possibility of some duration of harm (Table 2).

\section{Reported Coping Strategies}

Respondents were asked how they coped with their emotions after an incident and were allowed to select multiple coping strategies. Reports indicating "none" on emotional response were excluded from the analysis (42 reports). There were 217 selections in 196 reports. A coping strategy to the incident was used $62.8 \%$ (123 of 196; 95\% CI, $55.5 \%$ to $69.5 \%$ ) of the time. The coping strategies included talked about it $(52.0 \%)$; did nothing $(37.2 \%)$; told the patient $(17.9 \%)$; and did something else (3.6\%).

\section{Coping Strategy Versus Provider, Severity, and Duration} of Impact

For analysis, 2 categories were created: having a coping strategy and having no coping strategy. Having a coping strategy versus not having a coping strategy by provider type (physician/clinic staff) and sex (male/female) was examined. Table 3 shows the percentage of reports with a coping strategy by provider type and the coping strategy by sex for physicians only. A coping strategy was reported

Table 2. Emotional Response By Provider Type and Duration of Harm

\begin{tabular}{lccc}
\hline Emotional Response & $\begin{array}{c}\text { Reports } \\
\text { Submitted (n) }\end{array}$ & $\begin{array}{c}\text { Reported an Emotional } \\
\text { Response (n [\%]) }\end{array}$ & Difference (\%) \\
\hline By provider type & 100 & $74(74.0)$ & $-14.4($ Clinic staff - physicians) \\
Clinic staff & 138 & $122(88.4)$ & \\
Physicians & & 12.0 (Some duration - no duration) \\
Duration of harm & 154 & $48(90.6)$ & $0.5 \%$ to $23.5 \%$ \\
No duration & 53 & & \\
Some duration & &
\end{tabular}


Table 3. Number of Reports With an Emotional Response and the Resulting Coping Strategy By Provider Type, Female Providers, Physician Gender, Duration and Severity of Harm

\begin{tabular}{|c|c|c|c|c|}
\hline & $\begin{array}{l}\text { Reports With } \\
\text { an Emotional } \\
\text { Response (\%) }\end{array}$ & $\begin{array}{c}\text { Reports With } \\
\text { a Coping } \\
\text { Strategy }(\mathrm{n}[\%])\end{array}$ & Difference (\%) & $\begin{array}{c}\text { Confidence } \\
\text { Interval }\end{array}$ \\
\hline \multicolumn{5}{|l|}{ Provider type } \\
\hline Clinic staff & 74 & $54(73.0)$ & 16.4 (Clinic staff - physicians) & $1.9 \%$ to $30.9 \%$ \\
\hline Physicians & 122 & $69(56.6)$ & & \\
\hline \multicolumn{5}{|l|}{ Female providers } \\
\hline Clinic staff & 74 & $54(73.0)$ & 27.5 (Clinic staff - physicians) & $11.2 \%$ to $43.6 \%$ \\
\hline Physicians & 77 & $35(45.5)$ & & \\
\hline \multicolumn{5}{|l|}{ Physicians by sex } \\
\hline Male & 45 & $34(75.6)$ & 30.1 (Male physicians - female physicians) & $11.6 \%$ to $48.1 \%$ \\
\hline Female & 77 & $35(45.5)$ & & \\
\hline \multicolumn{5}{|l|}{ Duration of harm } \\
\hline No duration & 121 & $63(52.1)$ & 22.9 (Some duration - no duration) & $6.3 \%$ to $39.5 \%$ \\
\hline Some duration & 48 & $36(75.0)$ & & \\
\hline \multicolumn{5}{|l|}{ Severity of harm } \\
\hline No severity & 103 & $53(51.5)$ & 23.5 (Some severity - no severity) & $8.7 \%$ to $38.4 \%$ \\
\hline Some severity & 76 & $57(75.0)$ & & \\
\hline
\end{tabular}

more often when there was a possibility of some duration of harm $(P=.0002)$ and when there was a possibility of some severity of harm $(P=.006)$ (Table 3).

\section{Discussion}

Patient safety incidents affected all members of the clinic, including the staff. Overall, $82 \%$ of the incidents reported to the MSCP program indicated an emotional response. High frequencies of frustration and embarrassment were reported by both physicians and clinic staff. It is interesting to note the low levels of blame, shame, and self-doubt. This finding is in direct contrast to what New$\operatorname{man}^{21}$ found in his interviews with family physicians. He established self-doubt, disappointment, self-blame, and shame to be the most frequently reported emotions. This difference might be explained by the level of harm. In Newman's study, physicians were recalling their most memorable mistake, whereas in the MSCP study most reported incidents had no known harm or mild harm. Minor frustrations such as lost and misfiled results are easy to recognize and were reported in large numbers. ${ }^{33}$ This may account for the high rates of frustration. Issues such as misdiagnosis and lapses in judgment were reported less often. ${ }^{33}$ It may be that these issues are more associated with feelings of shame and self-doubt. Similar to Waterman et al's ${ }^{19}$ find- ing, an emotional response was not related to severity of harm. Even harmless or close-call incidents can evoke an emotional response. As well, an emotional response was more likely when there was duration of harm.

Men were more likely than women to report an emotional response. This study did not include male clinic staff. When provider type was controlled for, female and male physicians reported emotional responses equally. This is similar to $\mathrm{Wa}$ terman et al's ${ }^{19}$ findings of no sex differences for reported stress after near misses or minor errors. When female participants were analyzed alone, physicians were more likely to report an emotional response than clinic staff.

To cope with an emotional response, $52 \%$ talked to someone about the incident and $18 \%$ told the patient. These behaviors increased when there was a degree of severity or duration of harm. Talking about an incident is a form of coping with and making sense of what has happened. ${ }^{12,17}$ Recognizing and dealing with mistakes in a supportive environment is an essential precursor to dealing with mistakes systematically and holistically. ${ }^{22}$ Physicians who make mistakes need to be able to disclose to the patient, discuss with colleagues, and accept that they are fallible. ${ }^{3,21,34}$ Because of limited space on the 1-page reporting form, the fixed-choice coping strategy options did not al- 
low for rich data. Consequently we were unable to determine whom the respondents talked to about the incident or if what they told the patient was an act of disclosure or not. Although we were unable to ascertain whom the provider talked to, others have reported that it was most often a loved one or colleague. ${ }^{13,21,35}$

Clinic staff reported using a coping strategy to address an emotional response more often than physicians. Among physicians, men were more likely to use coping strategies than women. It is interesting that the physicians are more likely to have an emotional response but are less likely to report using a coping strategy. Women physicians were even less likely to report using a coping strategy than men. This lack of coping strategies puts physicians at risk for burn-out and depression. ${ }^{23}$

\section{Conclusion}

Patient safety incidents in primary care elicit emotional responses from all providers regardless of the severity of the incident. All provider types reported frustration, embarrassment, or both. In response to the emotion they reported, clinic staff were more likely than physicians to talk with someone or tell the patient about the incident. The emotional impact of incidents on family physicians and their staff requires further exploration. Creating a venue for physicians and clinic staff to discuss their emotions following a safety incident has the potential to decrease burnout and depression. Further research in this area is required.

Thank you to our coinvestigators, Trevor Theman, Peter Norton, Ward Flemons, Ross Baker, Ann Casebeer, Philip Hebert, Hilary Adams, Neil Drummond, John Cowell, Wendy Tink, Linda Poloway, and Steven Lewis, for their input.

\section{References}

1. World Alliance for Patient Safety. Report on the results of the web-based Modified Delphi Survey of the International Classification for Patient Safety. June 8, 2007. Available at http://www.who.int/ patientsafety/taxonomy/ps_modified_delphi_survey. pdf. Accessed January 18, 2012.

2. Wears RL, Wu AW. Dealing with failure: the aftermath of errors and adverse events. Ann Emerg Med 2002;39:344-6.

3. Wu AW. Medical error: the second victim. The doctor who makes the mistake needs help too. BMJ 2000;320:726-7.
4. Denham C. TRUST: the 5 rights of the second victim. J Patient Saf 2007;3:107-19.

5. de Vries EN, Ramrattan MA, Smorenburg SM, et al. The incidence and nature of in-hospital adverse events: a systematic review. Qual Saf Health Care 2008;17:216-23.

6. Baker GR, Norton PG, Flintoft V, et al. The Canadian Adverse Events Study: the incidence of adverse events among hospital patients in Canada. CMAJ 2004;170:1678-86.

7. Fischer MA, Mazor KM, Baril J, et al. Learning from mistakes. Factors that influence how students and residents learn from medical errors. J Gen Intern Med 2006;21:419-23.

8. Kaldjian LC, Forman-Hoffman VL, Jones EW, et al. Do faculty and resident physicians discuss their medical errors? J Med Ethics 2008;34:717-22.

9. Wu AW, Folkman S, McPhee SJ, et al. Do house officers learn from their mistakes? Qual Saf Health Care 2003;12:221-6.

10. Mizrahi T. Managing medical mistakes: ideology, insularity and accountability among internists-intraining. Soc Sci Med 1984;19:135-46.

11. West CP, Huschka MM, Novotny PJ, et al. Association of perceived medical errors with resident distress and empathy: a prospective longitudinal study. JAMA 2006;296:1071-8.

12. Engel KG, Rosenthal M, Sutcliffe KM. Residents' responses to medical error: coping, learning, and change. Acad Med 2006;81:86-93.

13. Wolf ZR, Serembus JF, Smetzer J, et al. Responses and concerns of healthcare providers to medication errors. Clin Nurse Spec 2000;14:278-87.

14. Scott SD, Hirschinger LE, Cox KR, McCoig M, Brandt J, Hall LW. The natural history of recovery for the healthcare provider "second victim" after adverse patient events. Qual Saf Health Care 2009; 18:325-30.

15. Christensen JF, Levinson W, Dunn PM. The heart of darkness: the impact of perceived mistakes on physicians. J Gen Intern Med 1992;7:424-31.

16. Penson RT, Svendsen SS, Chabner BA, et al. Medical mistakes: a workshop on personal perspectives. Oncologist 2001;6:92-9.

17. Aasland OG, Forde R. Impact of feeling responsible for adverse events on doctors' personal and professional lives: the importance of being open to criticism from colleagues. Qual Saf Health Care 2005;14:13-7.

18. Allman J. Bearing the burden or baring the soul: physicians' self-disclosure and boundary management regarding medical mistakes. Health Commun 1998;10:175-97.

19. Waterman AD, Garbutt J, Hazel E, et al. The emotional impact of medical errors on practicing physicians in the United States and Canada. Jt Comm J Qual Patient Saf 2007;33:467-476. 
20. Gallagher TH, Waterman AD, Ebers AG, et al. Patients' and physicians' attitudes regarding the disclosure of medical errors. JAMA 2003;289:1001-7.

21. Newman MC. The emotional impact of mistakes on family physicians. Arch Fam Med 1996;5:71-5.

22. Kennedy EM, Heard SR. Making mistakes in practice. Developing a consensus statement. Aust Fam Physician 2001;30:295-9.

23. Schwappach DL, Boluarte TA. The emotional impact of medical error involvement on physicians: a call for leadership and organisational accountability. Swiss Med Wkly 2009;139:9-15.

24. Sirriyeh R, Lawton R, Gardner P, et al. Coping with medical error: a systematic review of papers to assess the effects of involvement in medical errors on healthcare professionals' psychological well-being. Qual Saf Health Care 2010;19:e43.

25. Thurber AD, Busing N. Decreasing supply of family physicians and general practitioners. Serious implications for the future. Can Fam Physician 1999;45:2084-9.

26. Fernald DH, Pace WD, Harris DM, et al. Event reporting to a primary care patient safety reporting system: a report from the ASIPS collaborative. Ann Fam Med 2004;2:327-32.

27. Rosser W, Dovey SM, Bordman R, et al.. Medical errors in primary care: results of an international study of family practice. Can Fam Physician 2005; $51: 386-7$.
28. Phillips RL, Dovey SM, Graham DM, et al. Learning from different lenses: reports of medical errors in primary care by clinicians, staff, and patients: a project of the American Academy of Family Physicians National Research Network. J Patient Saf 2006;2:140-6.

29. Bhasale AL, Miller GC, Reid SE, et al. Analysing potential harm in Australian general practice: an incident-monitoring study. Med J Aust 1998;169:73-6.

30. O'Beirne M, Sterling PD. Medical safety and community practice: necessary elements and barriers to implement a safety learning system. Healthc Q 2009;12 Spec No Patient:141-6.

31. The R Project for statistical computing. Available at: http://www.r-project.org/. Accessed April 19, 2010.

32. Doran H, Bates D, Bliese P, et al. Estimating the multilevel Rasch model: with the lme4 package. J Stat Softw 2007;20:1-18.

33. O'Beirne M, Sterling PD, Zwicker K, Hebert P, Norton P. Safety incidents in family medicine. BMJ Qual Saf 2011;20:1005-10.

34. Fisseni G, Pentzek M, Abholz HH. Responding to serious medical error in general practice-consequences for the GPs involved: analysis of 75 cases from Germany. Fam Pract 2008;25:9-13.

35. Wilf-Miron R, Lewenhoff I, Benyamini Z, et al. From aviation to medicine: applying concepts of aviation safety to risk management in ambulatory care. Qual Saf Health Care 2003;12:35-9. 